\title{
Experimental study on vertical fire spread along a wooden façade
}

\author{
Mathieu Duny ${ }^{1,2}$, Dhionis Dhima $^{1}$, Jean-Pierre Garo ${ }^{2}$ and Hui-Ying Wang ${ }^{2}$ \\ ${ }^{1}$ Centre Scientifique et Technique du Bâtiment, Université Paris Est, Marne-la-Vallée, France \\ 2 Institut P', UPR CNRS 3346, Département Fluides, Thermique, Combustion, ENSMA, BP. 40109, \\ 86961 Futuroscope Chasseneuil, France
}

\section{CONTEXT}

The main purpose of these tests is to get some information on fire spread along a combustible façade in order to assess the ability of numerical codes [1] to simulate flame propagation. Many authors have already studied compartment fire with external flames for non-combustible façades [2-4] and also combustible façades [5, 6]. Studies on non-combustible façade allow to describe flames (flame depth, flame height, thermal actions, etc.) and to explain the influence of geometrical parameters (opening dimensions, "U" configuration, etc.) on flame shape and flame behaviour. These studies highlight the importance of some of these parameters on vertical spread and correlations are issued from these experimental studies. If many researches on combustible façades exist, it is difficult to find academic configurations with a large instrumentation and generally, these studies focus on a facade system involving complex combustible materials (insulation or composite). That's why it was decided to perform some large scale tests to study fire spread along a vertical wood wall.

\section{EXPERIMENTAL SET-UP}

A principle drawing of the experimental set-up is presented in Fig. 1. The fire room is made of lightweight concrete. As a façade, a fire resistant board is set on a steel frame structure. The total area of the façade is $2.5 \mathrm{~m} \times 4.9 \mathrm{~m}$. The compartment is $1.5 \mathrm{~m}$ on a side and $1.15 \mathrm{~m}$ high. One side of the compartment is completely open on the façade in order to ensure well-ventilated condition inside the compartment. This test rig is really similar to the British standard façade test which is a real fire propagation test. But in the present test there is no side wall along the façade. As you can see in Table 1, three different tests are carried out. The first test is made without any combustible cladding on the calcium silicate board in order to measure the temperature and the calorific on inert façade. In the second and third tests a cladding of $18 \mathrm{~mm}$ thick plywood is mounted directly onto the calcium silicate board, i.e. no ventilation cavity behind plywood. In these two tests, two different type of wood are used, respectively Birch wood and Okoumé (African wood), in order to observe the influence of the essence of the wood on flame propagation and on calorific values.

This is an Open Access article distributed under the terms of the Creative Commons Attribution License 2.0, which permits unrestricted use, distribution, and reproduction in any medium, provided the original work is properly cited. 

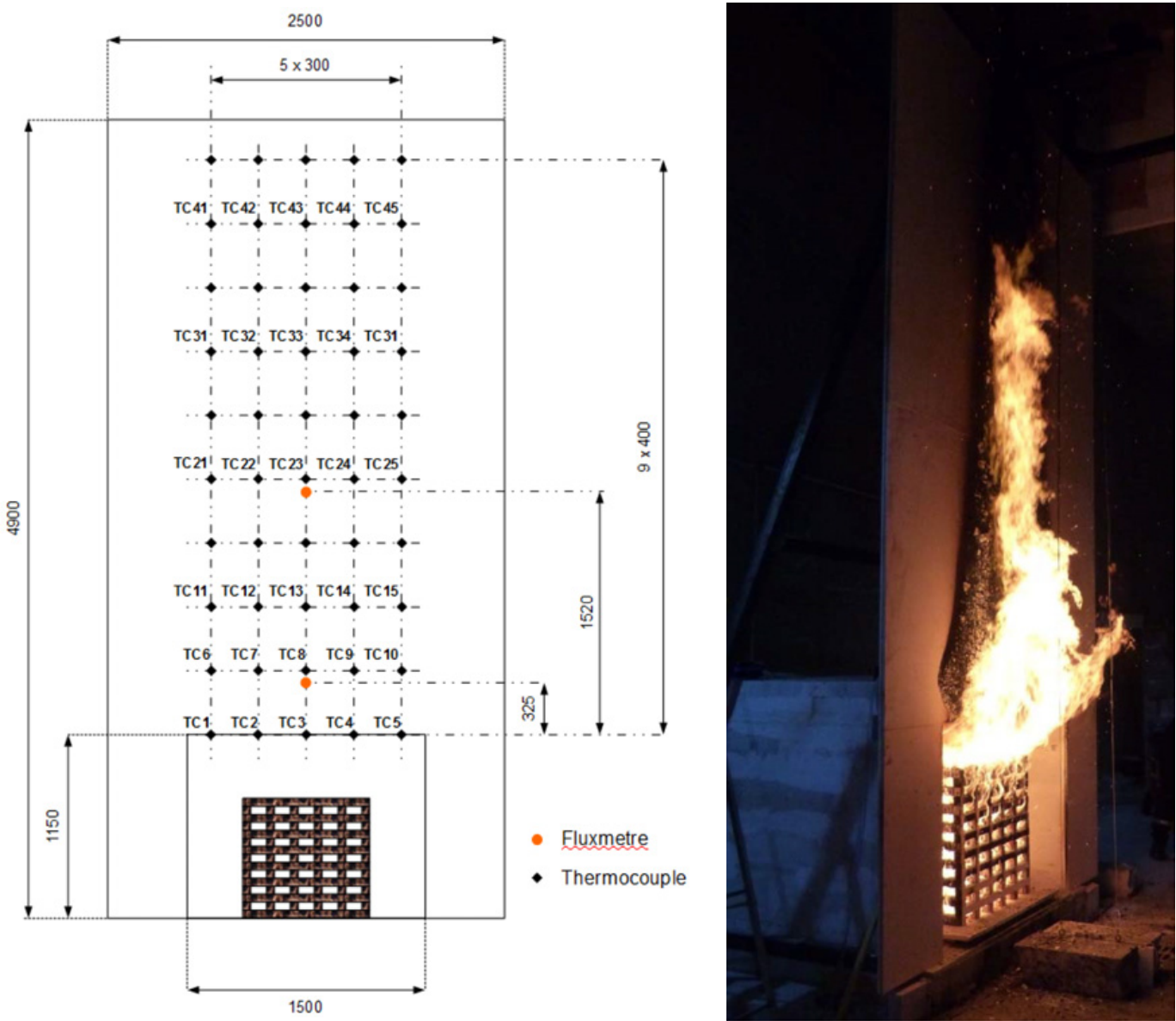

Figure 1. Experimental set-up.

Table 1. Description of tests.

\begin{tabular}{|c|c|c|c|}
\multicolumn{1}{c|}{} & Test_1 \& Test_2 & Test_3 et Test_5 & Test_4 et Test_6 \\
\hline Type of façade & Calcium silicate & Birch & Okoumé \\
\hline Thickness $(\mathrm{mm})$ & 13 & 18 & 18 \\
\hline Density $\left(\mathrm{kg} / \mathrm{m}^{3}\right)$ & 870 & 678 & 527 \\
\hline
\end{tabular}

\subsection{Scaling of the fire source}

The heat release rate (HRR) is deduced as follows:

$$
\mathrm{HRR}=\dot{m} \cdot \Delta H_{c}
$$

Where $\dot{m}$ is the mass loss rate of the wood crib measured during the test. In this study, it was supposed that the heat of combustion $\left(\Delta H_{c}\right)$ of the fire source is equal to $17.5 \mathrm{MJ} / \mathrm{kg}$. The theoretical HRR can be dimensioned before the test using a simple equation from the SFPE Handbook [7]. The equation of the mass loss rate commonly used for this type of fire is as follows:

$$
\dot{\mathrm{m}}=\frac{4}{D} m_{0} v_{p}\left(1-\frac{2 v_{p} t}{D}\right) .
$$




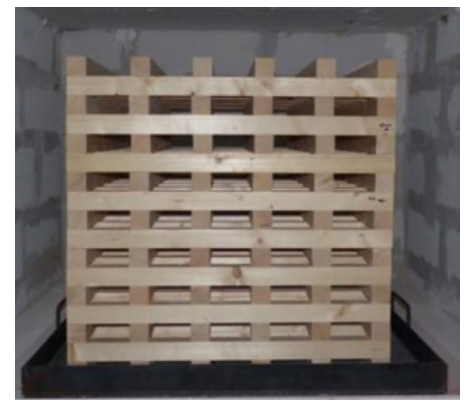

Figure 2. Picture of the wood crib used in the tests.

In this equation, $D$ is the stick thickness, $m_{0}$ is the initial mass, $\mathrm{t}$ is the time since ignition and $v_{p}$ is the fuel regression. Stick thickness (D) is dimensioned in order to obtain a maximum value of the HRR $(\mathrm{t}=0)$ of about $1500 \mathrm{~kW}$. This value is high enough to get external flames simulating a postflashover fire scenario and to obtain sufficient heat flux and temperature to ignite wood on the façade. In consequence, a $0.8 \mathrm{~m} \times 0.8 \mathrm{~m} \times 0.8 \mathrm{~m}$ wood crib constitutes the designed fire source (Fig. 2). Oilsoaked rags are used to ignite the fire.

The heat release rate (HRR) is obtained with two different methods:

- By measuring the mass loss during the test (Eq. (1))

- By collecting exhaust gases in a hood above the façade test rig (Eq. (3)).

$$
\mathrm{HRR}=\rho_{O_{2}} \dot{m}_{e} \Delta H_{O_{2}} \frac{\frac{X_{O_{2}}^{\infty}}{100}-\frac{X_{O_{2}}}{100} \frac{X_{N_{2}}^{\infty}}{X_{N_{2}}}}{1+(1.1-1)\left(1-\frac{X_{O_{2}} X_{N_{2}}^{\infty}}{X_{N_{2}} X_{O_{2}}^{\infty}}\right)} .
$$

In this equation, $\rho_{\mathrm{O}_{2}}$ and $\dot{m}_{e}$ are respectively the oxygen density (temperature dependent) and the exhaust volume flow. The quantity $\Delta H_{O_{2}}(\mathrm{MJ} / \mathrm{kg})$ is the amount of energy released per unit mass of oxygen consumed, generally taken equal to $13.1 \mathrm{MJ} / \mathrm{kg}$. Quantities $X_{O_{2}}^{\infty}$ and $X_{O_{2}}$ are the ambient and exhaust mass fractions of oxygen. $X_{N_{2}}^{\infty}$ and $X_{N_{2}}$ are the ambient and exhaust mass fractions of nitrogen.

\subsection{Measurement}

Tests are performed with a deep instrumentation. A series of $2 \mathrm{~mm}$ K-type thermocouples is placed at a distance of $25 \mathrm{~mm}$ from the façade. Two other series of 10 thermocouples are located respectively $30 \mathrm{~cm}$ and $60 \mathrm{~cm}$ from the façade. In addition, two total radiometers are located at two different levels. Figure 1 shows the location of the measuring devices on the surface of the specimens.

\section{RESULTS AND DISCUSSIONS}

\subsection{Heat release rate}

HRR deduced from mass loss rate (Eq. (1)) is plotted in Fig. 3 for each test. A technical issue occurred during Test_ 1 (blue curve) resulted in an inaccurate measurement of the mass. In consequence, the curve issued from this test diverges from the others. Test duration is approximately between 18 and 19 minutes. HRR evolution is similar in tests 2 to 4 . Fire grows linearly up to its maximum value. Moreover, maximum HRR is almost the same, close to the theoretical value ( $1567 \mathrm{~kW})$. Also, measured mass loss rates traduce a good repeatability of the fire source behaviour. 


\section{MATEC Web of Conferences}

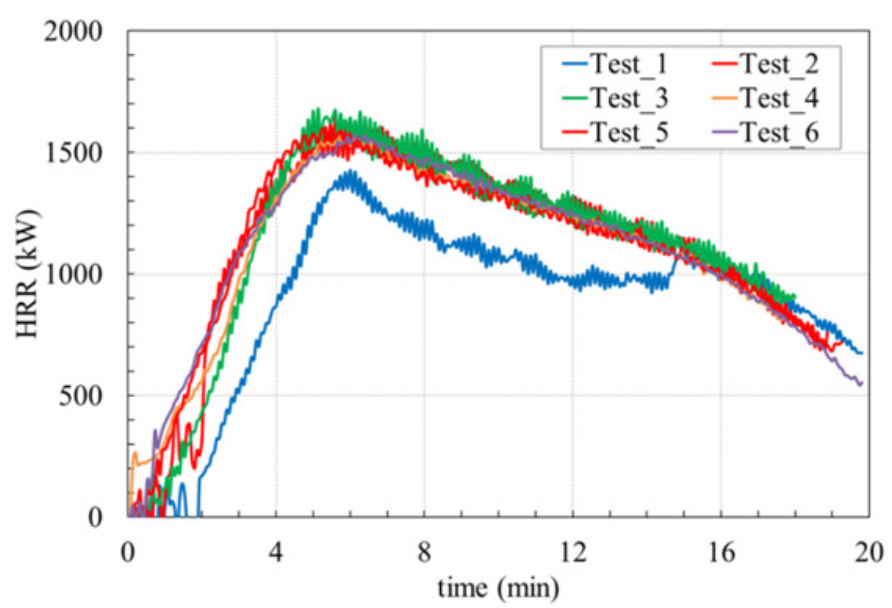

Figure 3. HRR deduced from mass loss rate.

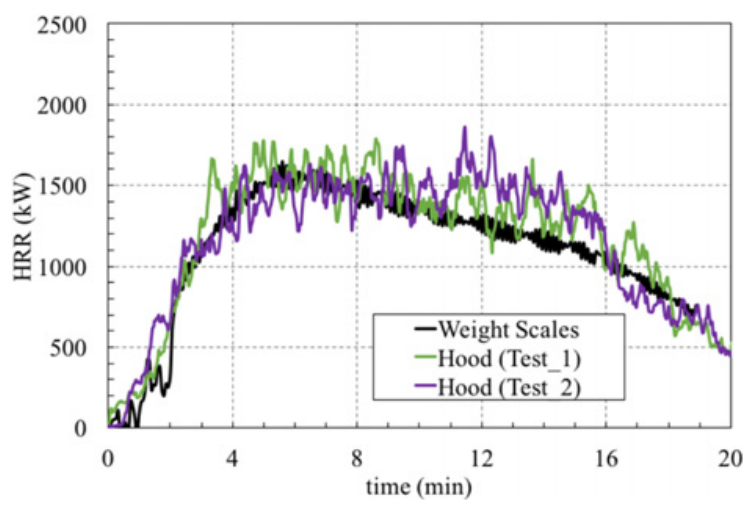

Figure 4. Comparison of HRR obtained using the two methods (Test_ 1 \& Test_ 2).

Note that HRR estimation from fuel mass loss rate is a useful method to verify test repeatability and to heat released by the wood crib. However, this method does not allow to estimate façade contribution i.e. heat released by the combustible façade after fire propagation.

Figure 4 represents a comparison of the two methods used to determine the HRR for Test_ 1 and Test_2. It shows similar results between the two methods for both tests. Indeed, growth phases (between 0 and 6 minutes) are really close and maximum values are almost equal. The steady state is quite similar for the three curves. While HRR obtained from the mass loss rate decreases slowly, HRR obtained from oxygen consumption into the hood seems to be constant before falling sharply and reaches the black curve. Moreover, we can see that results obtained with the second method (hood) are really close highlighting the repeatability of these tests.

Figure 5 shows the heat release rate obtained for Test_ 2 (inert), Test_ 3 (Birch) and Test_ 4 (Okoumé) using the gas analysis. We can clearly see the contribution of the combustible claddings for the three tests. It can be noted that the initial phase of the tests, up to 2 minutes is similar. After 3 minutes, for the combustible façade, the HRR increases of about $500 \mathrm{~kW}$ compared with the inert façade, for both Test_3 (Borch) and Test_ 4 (Okoumé). This contribution slowly decreases to the end of the test. It is really interesting to observe that the two combustible façades have the same contribution during the same time interval. These data are very important in order to validate numerical simulation. 


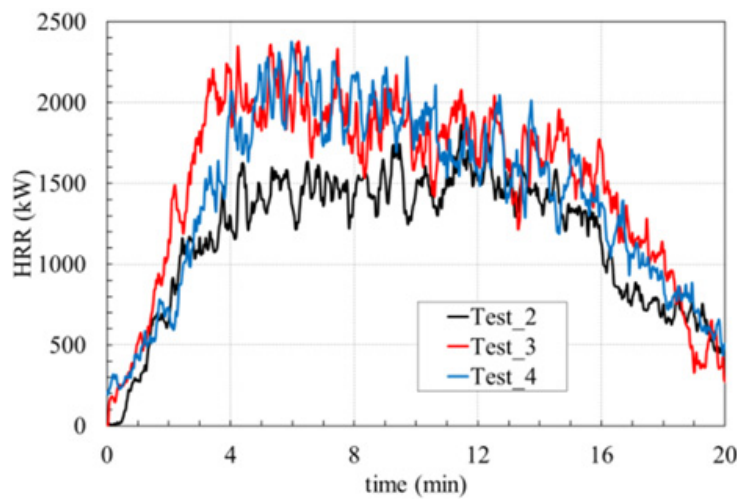

Figure 5. HRR measured in the hood during Test_2, Test_ 3 and Test_ 5 .

\subsection{Gas temperatures along the façade}

Thermocouples are used in order to compare thermal actions for the three tests. On Fig. 6, temperatures for Test_ 2 (inert façade), Test_ 3 (Birch façade) and Test_ 4 (Okoumé) are compared. For the three tests, the flame ejected through the opening is symmetric, and maximum temperatures are always located in the centreline of the façade. That's why only centreline temperatures are presented here.

During the three tests, temperatures rapidly increase and we can observe a steady state on temperature between 3 and 16 minutes. The lowest temperatures are obtained with the inert façade in the higher part of the façade due to the presence of flames in this area. However, in the lower part (from TC3 to TC13), temperatures are higher for the inert façade. This can be due to the accumulation of pyrolysis gases that reduces the combustion efficiency and move up the combustion area leading to a decrease of temperature at these locations for combustible façades.

We can observe that thermal actions are not equivalent for the tests with combustible claddings. Indeed, temperatures are higher with Birch wood. Moreover, vertical fire spread seems to be more important for this essence. During Test_ 3, temperatures at location TC 33 to TC 43 show that the flame spreads all along the façade and reaches the upper part of the test rig. Temperatures are near $800^{\circ} \mathrm{C} 4$ minutes after ignition $3.2 \mathrm{~m}$ above the opening. During Test_ 4, there is no flame at this location. It is important to see that thermal actions are lower during this test because heat release rates are similar for these two tests. This shows that the type of wood has a great influence on the flame spread.

\subsection{Fire spread over the façade surface}

As you can see on Fig. 7 and Fig. 8, flame shape is really symmetric. Visual observations after the test confirm that there is fire spread and charring up to the top of test rig for Birch wood (Test_ 3). Moreover, a large part of plywood burns or falls down directly above the opening. After Test_4, we can see that a smaller area burned. However, as observed on Fig. 5, the energy released by the combustion of this façade is exactly the same for both tests (Approximately $500 \mathrm{~kW}$ ). Thus, this may be due the heat of combustion. The Okoumé essence seems to have a higher value. Additional tests with a bomb calorimeter are planned in order to determine the heat of combustion. 
MATEC Web of Conferences
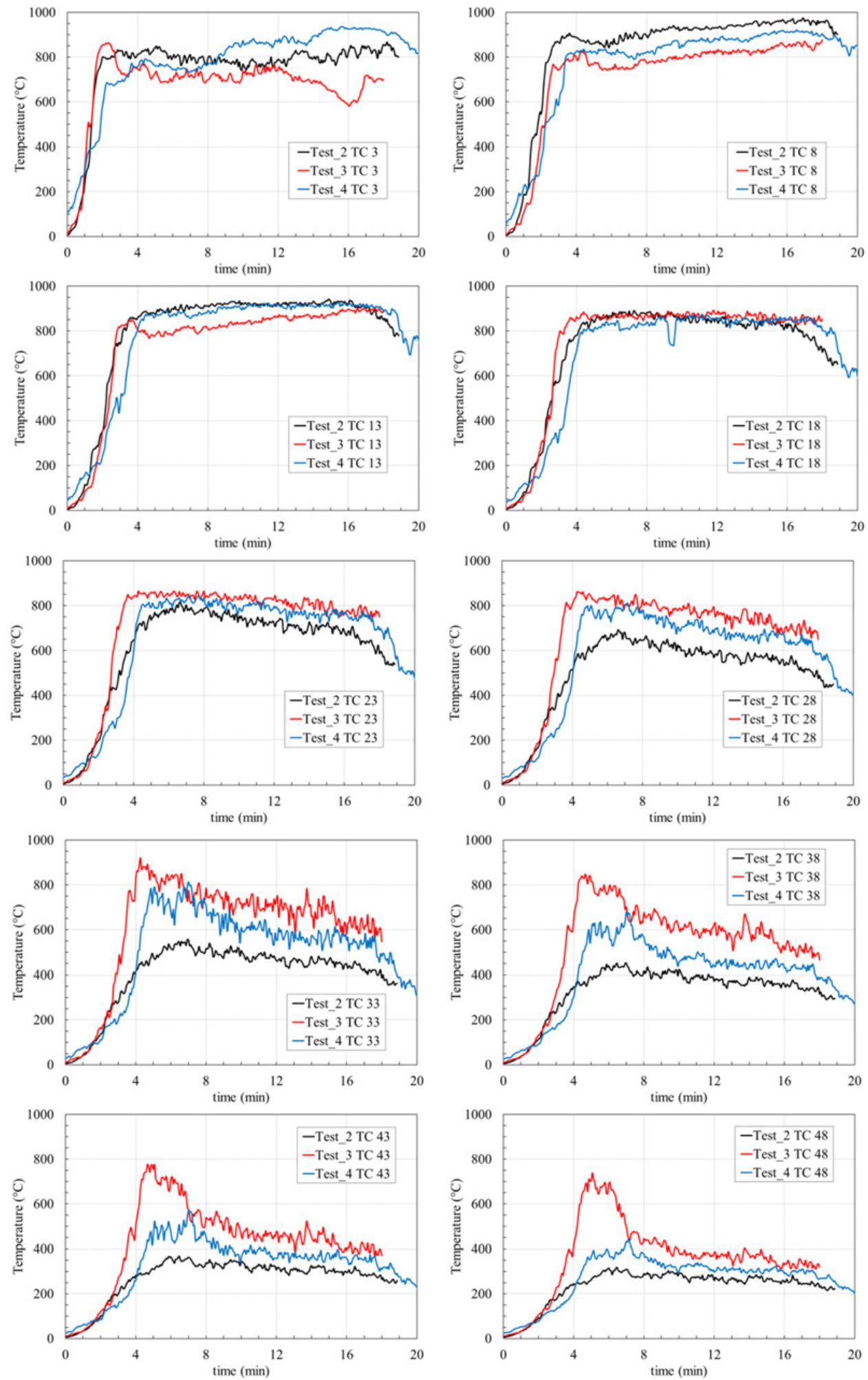

Figure 6. Comparison of temperatures in the centerline of the façade. 
$2^{\text {nd }}$ International Seminar for Fire Safety of Facades, Lund (Sweden), 2016

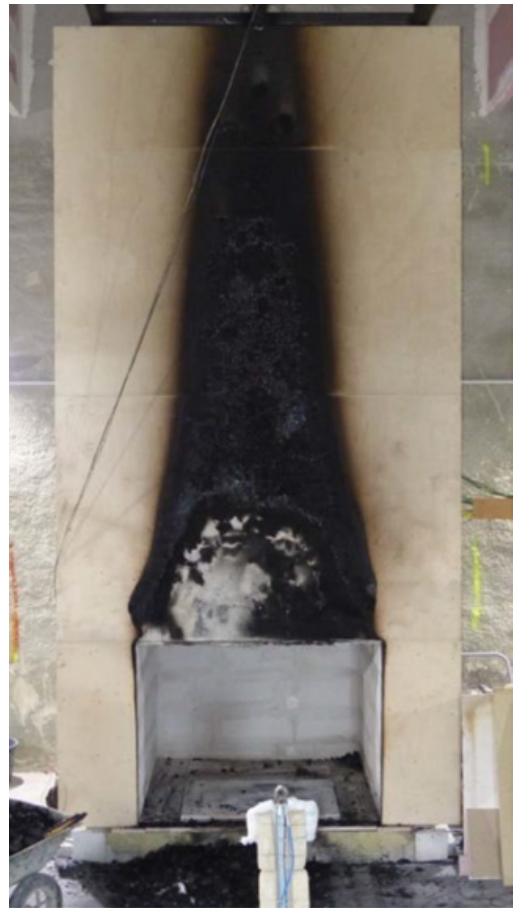

Figure 7. After Test_3.

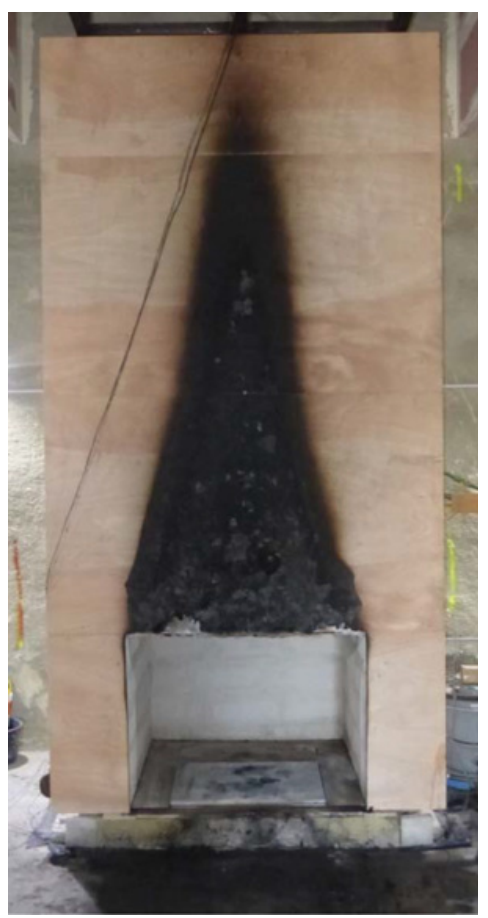

Figure 8. After Test_4. 


\section{CONCLUSION}

The aim of these tests was to perform an academic test in order to obtain a lot of measurements in order to validate fire models. These results give the possibility to compare experimental data with numerical predictions. Gas temperatures along the façade and heat release rates are the main results. A good repeatability was observed with the fire source behaviour. The use of two essences of wood was relevant. Whereas heat releases rates were identical during the two tests with combustible claddings, gas temperatures and observations post fire show that the vertical fire spread was really different.

\section{References}

[1] McGrattan, K., McDermott, R., Hostikka, S., Floyd, J., "Fire Dynamics Simulator (Version 6), user's guide", NIST Special Publication, 2013.

[2] Lu, K.H., Hu, L.H, Tang, F., Delichatsios, M.A., Zhang, X., He, L., "Facade flame heights from enclosure fires with side wall at the opening", Procedia Engineering, The 9th Asia-Oceania Symposium on Fire Science and Technology, 2013.

[3] Tang, F., Lu, K.H., Hu, L.H, Delichatsios, M., "Experimental study on flame height and temperature profile of buoyant window spill plume from an under-ventilated compartment fire", Journal of Heat and Mass Transfer, 2011.

[4] Lu, K.H., Hu, L.H, Tang, F., Zhang, X., He, L., "Experimental investigation on window ejected facade flame heights with different constraint side wall lengths and global correlation", Journal of Heat and Mass Transfer, 78, 17-24, 2014.

[5] Yoshioka, H., "Study of test method for evaluation of fire propagation along façade wall with exterior thermal insulation", Fire Science and Technology, 30, 27-44, 2011.

[6] Nishio, Y., "Experimental study on fire propagation over combustible exterior facades in Japan", MATEC Web of Conferences 9, 04001, 2013

[7] Babrauskas, V., "Heat Release Rate". In The SFPE Handbook of Fire Protection Engineering Third Edition, Chapter 3-1, 2002. 